\title{
Perforations of Gastro-Duodenal Ulcers in the Surgery Department " $A$ " at the University Hospital Point G Bamako
}

\author{
0. Sacko', S. Diallo², L. Soumaré1, M. Camara'1, S. Koumaré1, \\ M. Sissoko' ${ }^{1}$, S. Keita1, Carol ${ }^{1}$, D. Dakouo' ${ }^{1}$, M. Coulibaly', \\ M. Traoré3, G. Soumaré4, A. F. Traoré1, H. Dicko5, \\ Y. Dianessi' ${ }^{1}$ B. Traoré1, A. Koita ${ }^{1}$, Sanogo Zimogo' ${ }^{1}$ \\ ${ }^{1}$ Department of Surgery “A”, University Hospital of Point G, Bamako, Mali \\ ${ }^{2}$ Department of Surgery “B”, University Hospital of Point G, Bamako, Mali \\ ${ }^{3}$ Department of Gynecology-Obstetrics, University Hospital of Point G, Bamako, Mali \\ ${ }^{4}$ Department of Internal Medicine, University Hospital of Point G, Bamako, Mali \\ ${ }^{5}$ Department of Intensive Care, University Hospital of Point G, Bamako, Mali \\ Email: ousacko72@gmail.com
}

How to cite this paper: Sacko, O., Diallo, S., Soumaré, L., Camara, M., Koumaré, S., Sissoko, M., Keita, S., Carol, Dakouo, D., Coulibaly, M., Traoré, M., Soumaré, G., Traoré, A.F., Dicko, H., Dianessi, Y., Traoré, B., Koita, A. and Zimogo, S. (2019) Perforations of Gastro-Duodenal Ulcers in the Surgery Department " $A$ " at the University Hospital Point G Bamako. Surgical Science, 10, 265-270.

https://doi.org/10.4236/ss.2019.108028

Received: July 11, 2019

Accepted: August 5, 2019

Published: August 8, 2019

Copyright () 2019 by author(s) and Scientific Research Publishing Inc. This work is licensed under the Creative Commons Attribution-NonCommercial International License (CC BY-NC 4.0). http://creativecommons.org/licenses/by-nc/4.0/

\begin{abstract}
The purpose of this study was to investigate the clinical and therapeutic aspects of peritonitis by perforation of gastric and duodenal ulcer. This was a retrospective and descriptive study over 8 years $(2010-2018)$ which allowed to collect 54 cases of peptic ulcer. Included in the study were all patients with confirmed gastroduodenal perforation on histology or laparotomy. We collected 54 cases of peptic ulcer perforated s. The age group of $30-49$ years was the majority. The male sex was dominant with $90.7 \%$ of cases; the clinical picture was dominated by abdominal contracture associated with pain in $74.07 \%$ of cases. X-ray of the abdomen without preparation (AWP) revealed in $87.03 \%$ of cases of pneumoperitoneum. The perforation was in $68.52 \%$ of cases on the gastric antrum and in $31.48 \%$ on the duodenum. The surgical procedure used was the bank of excision, and a suture reinforcement epiploic in $68.52 \%$ of cases, a simple suture made in $31.48 \%$ of cases, the disease was marked by a fistula (1.90\%) and mortality was $5.55 \%$ of cases. The gastroduodenal ulcer perforation is potentially serious and responsible peritonitis whose surgical treatment involves the peritoneal toilet and sutures the puncture.
\end{abstract}

\section{Keywords}

Perforated Gastric or Duodenal Ulcer, Peritonitis, Surgery 


\section{Introduction}

Peptic ulcer is a defect more or less deeply digging the gastric or duodenal wall. It is the result of an imbalance between aggressive factors and protective factors at a specific point of the gastric or duodenal mucosa. During its evolution, it may be responsible for several complications among which the perforation leads to a breach in the stomach and/or duodenum thus causing peritonitis. Peritonitis by perforation of peptic ulcer is a relatively common medical-surgical emergency that requires a multidisciplinary approach involving the surgeon and intensivist. Its prognosis is serious if management is delayed with a mortality rate that can reach more than $50 \%$ beyond the first 24 hours [1]. For a dozen years, the management of peptic ulcer perforation was significantly changed due to three factors: the progress of medical treatment combining proton pump inhibitors, eradication systematic of Helicobacter pylori, the progress of resuscitation and the contribution of laparoscopic surgery. In developed countries, the incidence of gastroduodenal ulcer perforation decreased through better management of peptic ulcer disease. The ulcer perforation s peptic represents $5 \%$ of abdominal emergencies according to some authors [2] and occupies the second place of complications of the ulcer after the haemorrhage. In Mali Coulibaly, [3] reported in a study, conducted a frequency of $30 \%$ compared Per the digestive formations with a mortality rate of $5 \%$. We initiated this work in order to make a contribution to the study of this affection with the objective of determining the epidemiological, clinical aspects and the surgical management.

\section{Methodology}

This was a retrospective and descriptive study conducted in the Surgery A Department at Point-G Hospital in Mali. It took place over a period of 8 years (2010-2018). During the study period 54 cases of peptic ulcer perforation were collected.

Included criteria: all patients were included in the study with perforation of gastric or duodenal ulcer confirmed by histology and laparotomy.

Criteria of non-inclusion: Patients with perforation not located on the stomach or duodenum, tumor perforations and traumatic perforations were not included in the study. Incomplete medical records were not included in this study.

The clinical, para clinical, and therapeutic aspects have been studied. The medical records, the hospitalization record, the operative report, and the protocol of anesthesia served as a data support for the realization of this work.

\section{The Results}

As shown in Table 1, the age group 30 - 49 years was the majority, the average age was 37.5 years with extremes of 16 years and 83 years. The male represented $90.7 \%$ of cases $(\mathrm{n}=49)$ with 9.8 sex ratio in favor of men, 34 patients or $63 \%$ were illiterate. All patients, $100 \%$ of cases $(n=54)$ were admitted to the emer- 
gency department and $79.60 \%$ of these patients $(n=43)$ were referred by a general practitioner. The average time between onset of symptoms and surgical consultation was 72 hours. On admission $44.40 \%$ of patients $(n=24)$ had a WHO performance status grade 2 side. The lifestyle of patients: 13 patients or $24.10 \%$ of cases were smokers, $16.70 \%(n=9)$ were alcohol-smokers. A concept of taking NSAI was found in 11 patients or $20.37 \%$ of cases. Medical history, functional signs, examination signs and para clinical examinations are reported in Tables 2-5.

A disappearance of the pre liver dullness was found in 3 patients is $5.50 \%$. A admission $70.37 \%$ of patients $(n=38)$ had a body temperature above $38^{\circ} \mathrm{C}$. A

Table 1. Distribution of patients by age.

\begin{tabular}{ccc}
\hline Age & Effective & Percentage \\
\hline $15-29$ & 16 & 29.60 \\
$30-49$ & 30 & 55.60 \\
$50-69$ & 5 & 9.30 \\
$70-89$ & 3 & 5.60 \\
Total & $\mathbf{5 4}$ & 100 \\
\hline
\end{tabular}

Table 2. Medical history.

\begin{tabular}{ccc}
\hline Medical background & Effective & Percentage \\
\hline Confirmed gastric ulcer & 20 & 37 \\
Confirmed duodenal ulcer & 14 & 26 \\
Gastritis & 8 & 15 \\
Other & 12 & 22 \\
Total & 54 & 100 \\
\hline
\end{tabular}

Table 3. Distribution of patients according to functional signs.

\begin{tabular}{ccc}
\hline Functional signs & Effective & Percentage \\
\hline Diffuse abdominal pain & 39 & 72 \\
Epigastric pain & 8 & 15 \\
Vomiting + abdominal pain & 6 & 11 \\
Stopping of materials and gases & 1 & 2 \\
Total & 54 & 100 \\
\hline
\end{tabular}

Table 4. Distribution of patients according to physical signs.

\begin{tabular}{ccc}
\hline Physical signs & Effective & Percentage \\
\hline Epigastric Defense + pain in stabbing & 14 & 26 \\
Abdominal contracture + diffuse pain & 40 & 74 \\
Total & 54 & 100 \\
\hline
\end{tabular}


medical preparation was performed in all patients $100 \%$ of cases, it consisted of rehydration hydro-electrolytic, and dual antibiotic therapy. An X-ray of the abdomen without preparation (ASP) required for the diagnostic assessment showed pneumoperitoneum in $87.03 \%$ of cases $(n=47)$, it returned normal in $7.40 \%$ of cases $(n=4)$. The gastric antrum was the seat of the perforation in $68.50 \%$ of cases $(n=37)$ and the duodenum in $31.48 \%$ of cases $(n=17)$. The hole of the perforation was less than $2 \mathrm{~cm}$. in $92.60 \%$. We operated on $52 \mathrm{pa}$ tients or $96.30 \%$ of cases by laparotomy, and 2 patients $3.70 \%$ of cases by laparoscopy. The surgical procedure used is reported in Table 5.

Operative follow-up was simple in $85.15 \%$ of cases $(n=46)$. Morbidity was marked by one case of fistula $(1.90 \%)$ and mortality was $5.55 \%$ of cases $(n=3)$.

\section{Discussion}

The perforation of a peptic ulcer is a serious complication of peptic ulcer disease. Here we report the results of a retrospective and descriptive study. The review of the literature reports a frequency of peritonitis perforation of peptic ulcer which is variable between $3 \%-17 \%$ according to the studies. The $30 \%$ of our series are statistically superior to the $10 \%$ and $15 \%$ respectively reported by Cougard and al [2] in France and Alamowitch and al in Russia [4]. The male predominance of gastroduodenal ulcer perforation has been reported in several series. In the study conducted by Youssef et al. [5] in Tunisia perforation involved $96.9 \%$ of men. Cougart [2] found that $71.36 \%$ of cases were men. According to Soule JC [6], male predominance is explained by the presence of parietal cells in the stomach in greater numbers than in women. These cells secrete the primary compound which has a very high concentration of chloridic acid. It is also attributed psychological factors and the prevalence of smoking in the male population. Recent literature involves Helicobacter pylori as one of the main causes of perforation peritonitis of peptic ulcer disease. Perforation is associated with Helicobacter pylori infection in $47 \%$ - 97\% [7]. His diagnosis is based on biopsy and serology. The biopsy was not performed in all our patients which allowed us to determine the incidence of Helicobacter pylori in our series. Other factors contribute to increasing the morbidity of this condition such as tobacco. In our series $16.70 \%$ $(n=9)$ of patients were smokers against $74 \%$ of smoking in series Boey J [8]. Taking gastro-toxic drugs (non steroidal anti-inflammatory) can cause perforation of a peptic ulcer even in the absence of Helicobacter pylori, this risk is multiplied by 3 to 4 times. In our series there was a concept of taking NSAI in $20.37 \%(\mathrm{n}=11)$ of patients, against $20 \%$ of cases reported by Boris Alamo with

Table 5. Surgical procedure.

\begin{tabular}{ccc}
\hline Surgical procedure & Effective & Percentage \\
\hline Excision of the margins + suture + epiplooplasty & 37 & 68.52 \\
Simple suture & 17 & 31.48 \\
Total & 54 & 100 \\
\hline
\end{tabular}


[4]. In our study the confirmed gastric ulcers accounted for $37 \%$ of cases and duodenal ulcer $18.50 \%$ of cases. This result is similar to the $18 \%$ confirmed ulcer reported in the Boey J series [8]. The delay between the appearance of the first signs and the medical consultation is important to specify because it can condition the therapeutic management. In the European series this delay is short (10 hours), it was 48 hours in our series. This delay of consultation is explained in our developing countries by the socio-economic conditions, the geographical distance and the scarcity of surgical center. The clinical diagnosis of peritonitis by perforation of gastric and duodenal ulcer was easy in most series because a careful clinical examination and a well-conducted interrogation make it possible to have a diagnostic suspicion. It was mentioned in our series in $74.07 \%$ of patients who presented a table of diffuse abdominal pain associated with abdominal contracture. An epigastric defense with stabbing pain was found in $25.9 \%$ of our patients. Paraclinical examination of first intention was the radiography of the abdomen without preparation (AWP). Most of the authors have asked it. In our series it revealed a pneumoperitoneum in $87.03 \%$ of cases, this result is close to the $74 \%$ of cases of pneumoperitoneum reported by Boey [8]. It was not contributive in $7.40 \%$ of cases in our series. The principles of surgical management of peptic ulcer perforation are the same in most of the series, the channel can first change, these principles consist after preoperative medical preparation is carried out intraoperatively a peritoneal lavage and repair of the lesion (perforation). At admission $65 \%$ of patients in our series had MPI $\leq 26$ in our series all patients underwent preoperative medical preparation, $96 \%$ of patients in our series were operated by laparotomy and $4 \%$ by laparoscopy. In the series reported by Boris Alamowich [4] all patients were operated on laparoscopically, i.e. 100\% of cases. The difference with our results reflects the experience of different surgery teams and the unavailability of emergency Laparoscopic surgery equipment in Mali. In our study the perforation was located respectively in $68.52 \%$ on the gastric antrum and in $31.48 \%$ on the duodenum. In the series reported by T.T. Tran [7] the location of the perforation on the gastric antrum was $92 \%$ and that of the duodenum $8 \%$ of cases. The gastric location of the perforation was the most common in our series; it is explained by the high percentage of gastric perforation in our series. The surgical procedure used in our series was excision + suture the banks of the perforation, with strengthening epiploic in $68.52 \%$ and the simple suture performed in $31.48 \%$. It did not seem necessary to associate the suture with a vagotomy in an emergency context and given the effectiveness of the eradication treatment of Helicobacter Pylori. This medical treatment consisted in our study of the use of a triple therapy including a proton pump inhibitor and a double antibiotherapy (amoxicillin and clarythromycin). The simple $85.15 \%$ follow-up and the $5.55 \%$ mortality observed here correspond to those of the large series [5] [7]. The morbidity was marked by a case of digestive fistula (1.99\% of cases) which required a recovery. The average hospitalisation of 9 days observed in our series corresponds to that reported by certain authors [1] [3]. 


\section{Conclusion}

The perforation of gastric or duodenal ulcer is responsible for a potentially severe peritonitis. The surgical procedure of its treatment consists of peritoneal lavage, suture of the perforation opening. Its prognosis is correlated with the speed of its management.

\section{Conflicts of Interest}

The author declares no conflicts of interest regarding the publication of this paper.

\section{References}

[1] Anouar, E.G. (2016) Peritonitis by Perforation of Peptic Ulcer about 22 Cases. Thesis of Med Rabat, Number 386, 60-125.

[2] Cougard, P., Barrat, C.H., Gagnel, F., et al. (2000) Laparoscopic Treatment of Duodenal Ulcer Perforations as a Result of the SFCL Multicenter Investigation. Annales de Chirurgie, 125, 726-731. https://doi.org/10.1016/S0003-3944(00)00267-4

[3] Coulibaly, I.S. (2005) Perforations of Gastro-Duodenal Ulcer at CHU Gabriel Touré. Thesis of Med Bamako, Number 19.

[4] Alamowitch, J.M., Aouad, K., Sellam, P. and Fournestraux, J. (2000) Laparoscopic Treatment of Perforated Duodenal Ulcer: Feasibility and Outcome. Gastroentérologie Clinique et Biologique, 24, 1012-1017.

[5] Youssef, S., Helara, W., Ghrissi, K., et al. (2005) Treatment of Perforated Duodenal Ulcers by Laparoscopic Epidemiological and Clinical Aspects Tunis, Surgery Association. 17-30.

[6] Soul, J. (1990) Mechanism of Defense of the Gastroduodenal Mucosa and Pathophysiology of Ulcerative Disease. In: Dive, Ch., Ed., Progress in Hepato Gastroenterology, Doin, Paris, 35-57.

[7] Tran, T.T. and Quandallé, P. (2002) Treatment of Perforation of Peptic Ulcer by Simple Suture Followed by Eradication of Helicobacter Pylori. Annales de Chirurgie, 127, 32-34. https://doi.org/10.1016/S0003-3944(01)00669-1

[8] Boey, J. and Wong, J. (1987) Perforated Duodenal Ulcers. World Journal of Surgery, 11, 319-324. https://doi.org/10.1007/BF01658109 